(C) 2018

\title{
Seasonal dynamics of nutrients in soil and change of their ratio depending on hydrothermal conditions of the year
}

Gladkikh Ye. ${ }^{1}$, Revtie-Uvarova A. ${ }^{2}$, Panasenko Ye. ${ }^{3}$

NSC "A.N. Sokolovsky Institute of soil science and agrochemistry», Chaikovska Str., 4, Kharkiv, 61024, Ukraine; e-mail: ' $y e . h l a d k i k h @ u k r . n e t,{ }^{2} a l i n a \_r e v @ m e t a . u a,{ }^{3}$ panasenko-evgeniy@rambler.ru

The purpose. To determine regularities of seasonal dynamics of nutrients and features of their disproportionation in soil depending on hydrothermal conditions of the year. Methods. Field, laboratoryanalytical, statistical analysis. Results. Essential variance is determined in seasonal dynamics of stores of mineral nitrogen and moisture of soil in years contrasting on conditions moisture security, in particular, in intensity of decrease of stores of mineral nitrogen during vegetation, ratio nitrate and ammonium nitrogen according to the profile of soil, and efficiency of use of nitrogen and moisture by plants. Conclusions. The gained results proved essential lowering activity of use of mineral nitrogen by plants in conditions of stressful drought and predominance in the structure of mineral nitrogen of its ammonium forms, especially in the end of vegetation. The effective use of nitrogen and moisture of soil takes place at optimization of root nutrition of plants due to importation of fertilizers, in particular, accumulation of residual phosphate in soil

Key words: abiotic stresses, hydrothermal conditions, nutrients, seasonal dynamics, adaptive potential.

Introduction. The issue of increasing resistance to extreme factors is becoming more important. The relevance of finding activities that would reduce the influence of abiotic stresses (mainly droughts and high temperatures) on the implementation of the adaptive potential of crops, in particular cereals, is increasing.

The content of sufficient moisture in the soil is a prerequisite for the normal development of plants and has a great influence on the supply of nutrients in them. The negative effect of re-wetting or overgrounding on the absorption and redistribution of nutrients may be manifested in the unilateral increase in the availability of certain ions, in particular iron salts and manganese, the accumulation of which in plants in this case reaches a toxic level or vice versa in the manifestation of a significant deficit in the flow of physiologically important nutrients.

Researches of scientists have proved that the content of nutrients in the soil, their redistribution by profile and the efficiency of use by agricultural plants depends on abiotic factors, in particular, hydrothermal conditions of the year. Kadichegova [1] proved that, for example, contribution to the dynamics of nitrate nitrogen of meteorological conditions (rainfall and average temperature of air) is 69$74 \%$, to a lesser extent of mineral fertilizers influence $-1-6 \%$ depending on the hydrological conditions of the year.

Amtmann and Blatt [2] prove that even in well-fertilized fields prolonged drought can lead to reduced mobility and absorption of certain nutrients.

Sardans $\mathrm{J}$. and others have tested the hypothesis that drought intensification changes the availability of trace elements: $\mathrm{Fe}, \mathrm{Mg}, \mathrm{Mo}, \mathrm{S}$, as well as their concentration and accumulation in ecosystems. Drought increases the total concentration of $S$ in the soil and the saturation of the soil exchange complex of $\mathrm{Fe}, \mathrm{Mg}$ and $\mathrm{Mg}$. Such changes concentration elements in soil were associated with a decrease in plant absorption, but not with an increase in the activity of enzymes in the soil, which actually decrease in more drought conditions [3, 4].

The mineral and nutrient state of plants plays a decisive role in increasing the resistance of plants to environmental factors, given that nutrients are needed not only for better growth and development of plants, but also for mitigating various kinds of abiotic stresses, such as stress drought [5]. 
Consequently, the interdependence of the redistribution of mineral elements (macro- and micro-) and their availability to plants from hydrothermal environmental conditions (moisture provision and temperature regime of the soil) and, on the contrary, the effectiveness of the use of moisture from the optimal content of nutrients, especially in the critical phases of growth and development of plants. Currently, the results of studies on the patterns of changes in the content and redistribution of nutrients in the soil under the conditions of abiotic stresses, in particular stress droughts, were little represented in the scientific literature, which impedes the effective application of fertilizers and the use of soil moisture. Optimizing nutrition of the crops and, in particular, the timely supply of nutrition elements to plants and their effective use is essential.

The purpose of research is to determine the regularities of the seasonal dynamics of the elements of nutrition and the peculiarities of their redistribution in the soil depending on the hydrothermal conditions of the year as the fundamental basis for optimizing the supply of agricultural crops, especially during critical periods of their growth and development under abiotic stress conditions.

Materials and methods of research. To achieve the goal of researches were carried out analyzing and generalization of materials and results long-term stationary field experiment, which was founded in 1969 on chernozem typical on the conditions of the experimental farm "Grakivske" (NSC "Institute for Soil Science and Agrochemistry research named after O.N. Sokolovsky"). The dependence of the content of macronutrients in the soil on the annual rainfall in the seasonal dynamics was studied on various agrochemical backgrounds, which were created with using of mineral fertilizers in the reserve (after 1983) and systematically. The method of creating agrochemical backgrounds is presented in the article [6].

To achieve the goal of investigate the effectiveness of early spring top dressing of agricultural crops by nitrogen in years differing by hydrothermal regime, as well as the effect of residual phosphate fertilizers on the use of soil moisture and the determination of features of redistribution of macroelements into the soil profile in seasonal dynamics was laid micro field experiment. Investigation of seasonal dynamics and migration of soil elements of nutrients, mainly of mineral nitrogen and mobile forms of phosphorus, was conducted in contrast to the conditions of humidity in years - in 2016 the average annual precipitation was $600 \mathrm{~mm}$, in 2017 - $262 \mathrm{~mm}$.

The scheme of the micro field experiment is as follows:

1. Control (without fertilizers);

2. Manure (140 t/ha) $+P_{1800}$ (in reserve, aftereffect 1983);

3. Manure (140 $t / h a)+P_{1800}$ (in reserve, aftereffect 1983) $+N_{60}$ (early spring top-dressing);

4. Manure (140 t/ha) $+\mathrm{N}_{1800} \mathrm{P}_{1800} \mathrm{~K}_{1800}$ (in reserve, aftereffect 1983).

5. Manure (140 t/ha) $+N_{1800} P_{1800} K_{1800}$ (in reserve, aftereffect 1983) $+N_{60}$ (early spring topdressing).

The selection of soil samples was carried out in early May and in late July with a depth of $0-100 \mathrm{~cm}$ layer $(0-20 \mathrm{~cm}, 20-40 \mathrm{~cm}, 40-60 \mathrm{~cm}, 60-80 \mathrm{~cm}, 80-100 \mathrm{~cm})$ using agrochemical drill.

Laboratory-analytical studies were conducted according to standardized methods. For achieve the purpose of research in soil samples were determined the following indicators: soil moisture; the content of mineral nitrogen (DSTU 4729:2007); mobile forms of phosphorus by Chirikov (DSTU 4115:2002). Statistical and mathematical data processing was performed using the program of STATISTICA 6.

The results of research. The harmful effects of abiotic factors can be minimized by optimal and balanced supply of mineral nutrients to plants, despite their natural resistance to stress droughts and abnormal temperatures. Existing research results indicate that the mineral-nutrient state of plants plays a decisive role in increasing their resistance to stress factors [7]. Optimal nutrition and agrotechnique significant impact on the circulation of water in plants what is a very effective method of drought controlling. When nutrients in the soil in low and unbalanced concentrations, plants should absorb more water for receive the same amount of mineral elements for their metabolism, which would get from the soil of ensuring optimal nutrients. On the other hand, under insufficient moisture provision conditions, plants can not obtain optimal amounts of nutrients, which negatively affect the general plants condition, especially their yield and quality. 
Nitrogen is an important component of the structural, genetic and metabolic compounds of plants [8,9] from the total amount of nutrients which absorbed by the roots of plants $80 \%$ are nitrogen [8]. The absorption and using of nitrogen by a plant during water stress is very important for the normal growth and development of plants. Waraich et al. [10] showed that the possible mechanism for minimizing adverse effects of drought is to increase the efficiency of soil moisture utilization by improving the supply of mineral nitrogen.

Investigation of the seasonal dynamics of mineral nitrogen reserves in the meter layer of chernozem typical indicates a gradual its decrease during growing period due to a number of factors: the use of nitrogen by plants for the formation of crops, the participation of nitrogen in biochemical transformations by microorganisms and leaching it out of the profile. The maximum reserves of mineral nitrogen (fig. 1, 2) in the field experiment are determined on the variant with the high doses of phosphorus applied in reserve (total amount of applied phosphate fertilizers is $1800 \mathrm{~kg} / \mathrm{ha}$ ), what contributes to the formation of residual phosphorus in the soil, which increases its overall cultivation, effective fertility and contributes to the intensive formation of "extra nitrogen". Such patterns are characterising of both years of research (2016 and 2017), but some differences over the years have been identified, due to a significant reduction in the average annual rainfall in 2017.

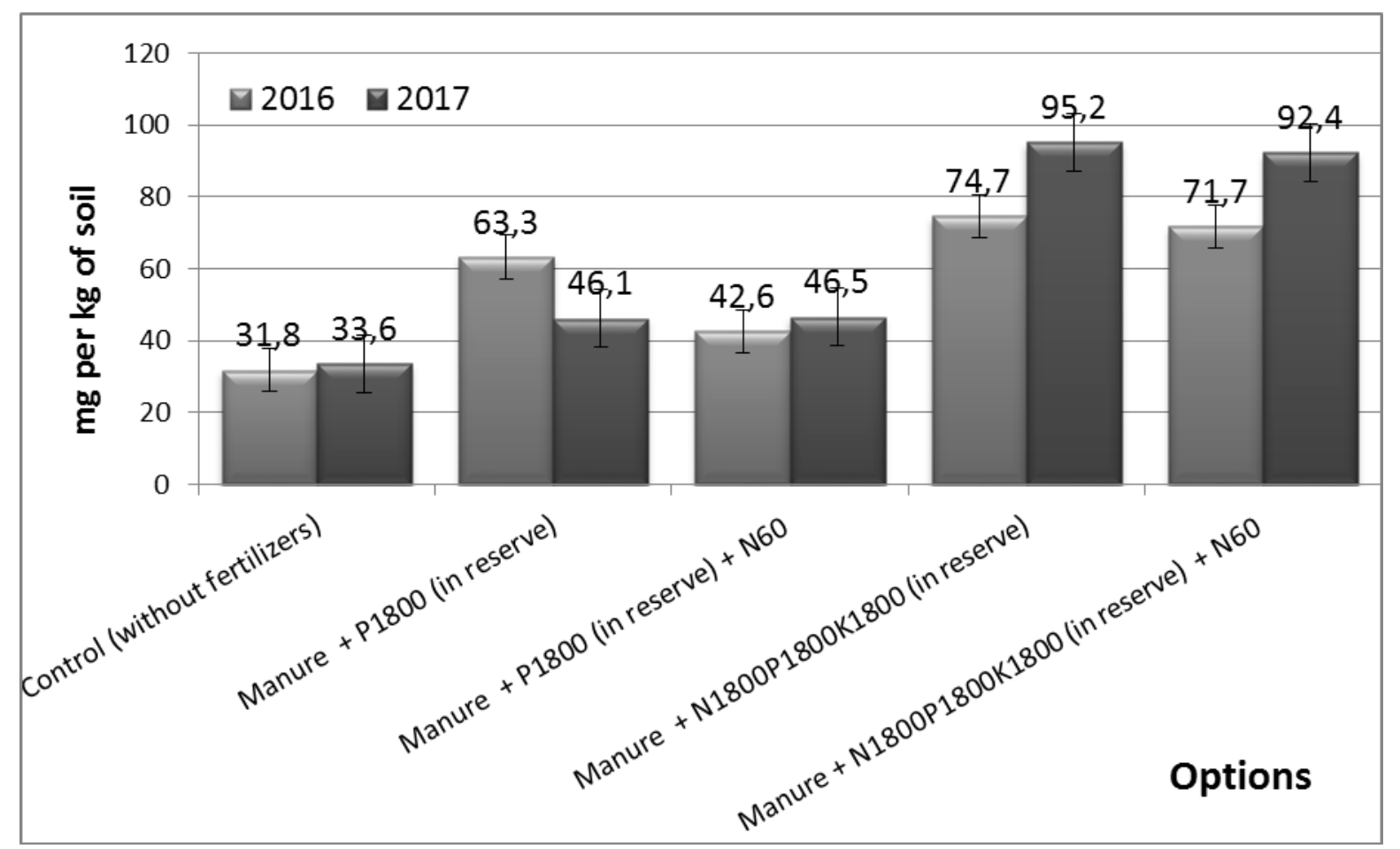

Fig. 1. Mineral nitrogen reserves in the layer of $0-100 \mathrm{~cm}$ in the chernozem typical at the beginning of the growing of agricultural crops 


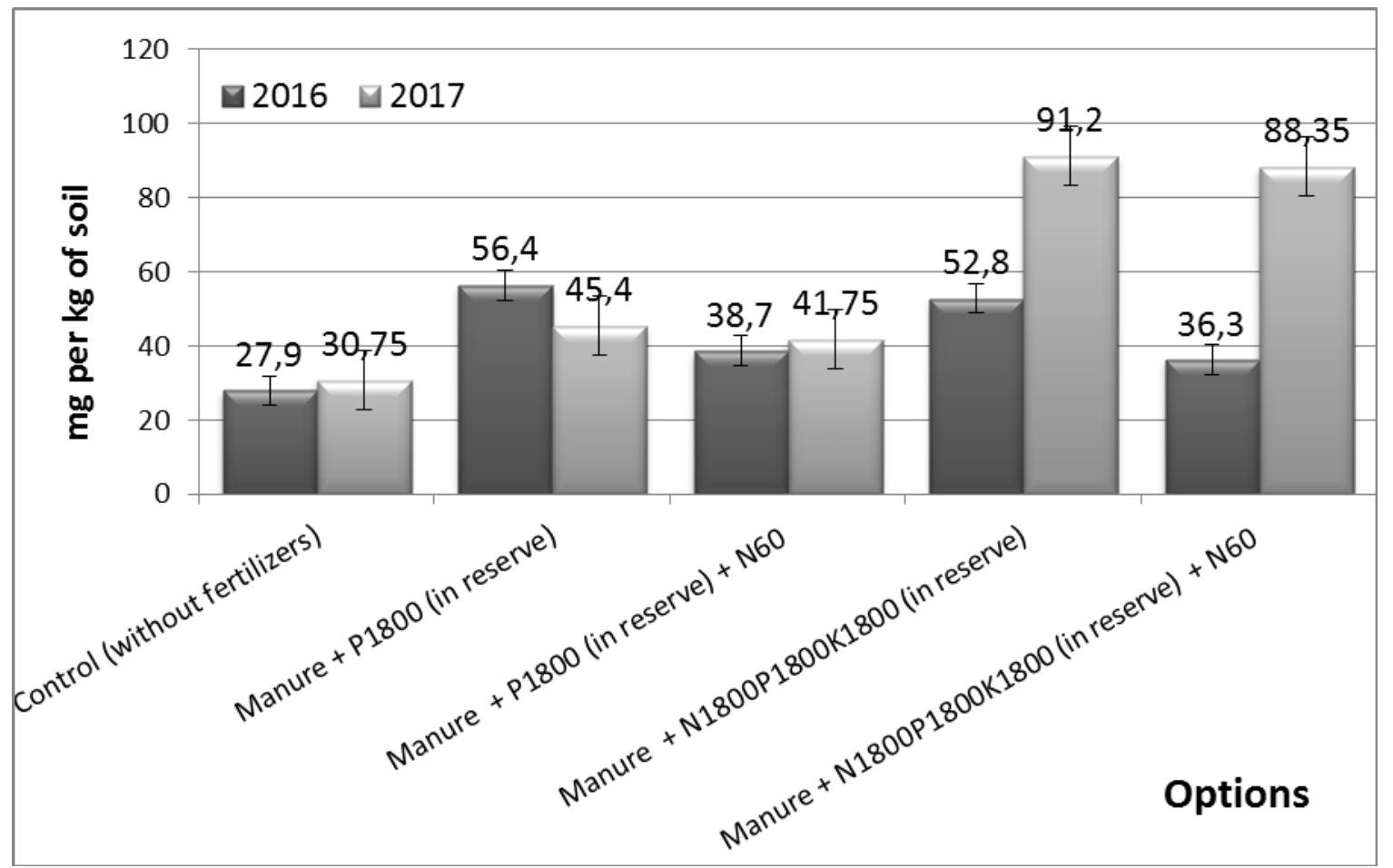

Fig. 2. Mineral nitrogen reserves in the layer of $0-100 \mathrm{~cm}$ in the chernozem typical in the end of the growing of agricultural crops

Residues of mineral nitrogen in the options with nitrogen top-dressing $\left(\mathrm{N}_{60}\right)$ as against background of manure $+\mathrm{P}_{1800}$ and against background of manure $+\mathrm{N}_{1800} \mathrm{P}_{1800} \mathrm{~K}_{1800}$ in 2017 were significantly higher than in 2016. In the dry year after top-dressing, the nitrogen reserves in the soil were higher at the beginning of the vegetation by 1.3 times and 1.7-2.5 times at the end of the vegetation. The intensity of the decrease of mineral nitrogen reserves from the beginning of May to the end of July also differed over the years: in arid 2017, nitrogen reserves in the $0-100 \mathrm{~cm}$ layer of soil decreased by $4.2-4.4 \%$, in 2016 by $29-49 \%$, which indicates a decrease in nitrogen utilization by plants in adverse hydrothermal conditions of the year.

It should be noted that high nitrogen reserves in 2017, especially at the end of vegetation, were maintained mainly due to the content of its ammonium forms - the ratio of $\mathrm{N}-\mathrm{NO}_{3}: \mathrm{N}^{-\mathrm{NH}_{4}}$ in the upper layers of the soil $\left(0-20\right.$ and $20-40 \mathrm{~cm}$ ) was $0.1-0.6$, with the fact that in 2016 the ratio of $\mathrm{N}-\mathrm{NO}_{3}: \mathrm{N}-\mathrm{NH}_{4}$ in the soil at the end of the vegetation ranged from 1.9-5.0.

Obviously, a significant reduction in the annual rainfall in 2017 by $340 \mathrm{~mm}$ compared with 2016 was reflected in the biological and physical-chemical processes of the soil and, consequently, the absorption and transformation of nitrogen fertilizers. Whereas the plants are able to absorb nitrogen predominantly in nitrate form, after nitrogen top-dressing in the first place plants used the most accessible form of nitrogen - nitrate, both in a favorable and unfavorable for moisture year. The transformation of ammonium nitrogen, probably due to inhibition of microbiological processes in arid 2017 year, also inhibited the oxidation of ammonium-containing compounds to nitrates, which explains their conservation in a 0-100 $\mathrm{cm}$ of soil layer to the end of the vegetation and cardinally distinguishes the dry year from optimum for moisture. Such regularities have already been obtained by us in previous studies [11].

In the years of contrasting by hydrothermal conditions, the study of nitrate nitrogen seasonal dynamics and the peculiarities of its redistribution on the soil profile become important. Because during the years with optimal moisture or in case of overfilling, there is a danger of leaching nitrates beyond the profile and its unproductive losses. In years with extreme drought, the intensity of nitrate nitrogen using by plants will depend on the amount of productive moisture in the soil and the balance of nutrition with other trace elements. In all studied options of the field experiment on chernozem typical, a gradual reduction of nitrate nitrogen content from spring to autumn, regardless of the year of research, is logical (fig. 3, 4). 


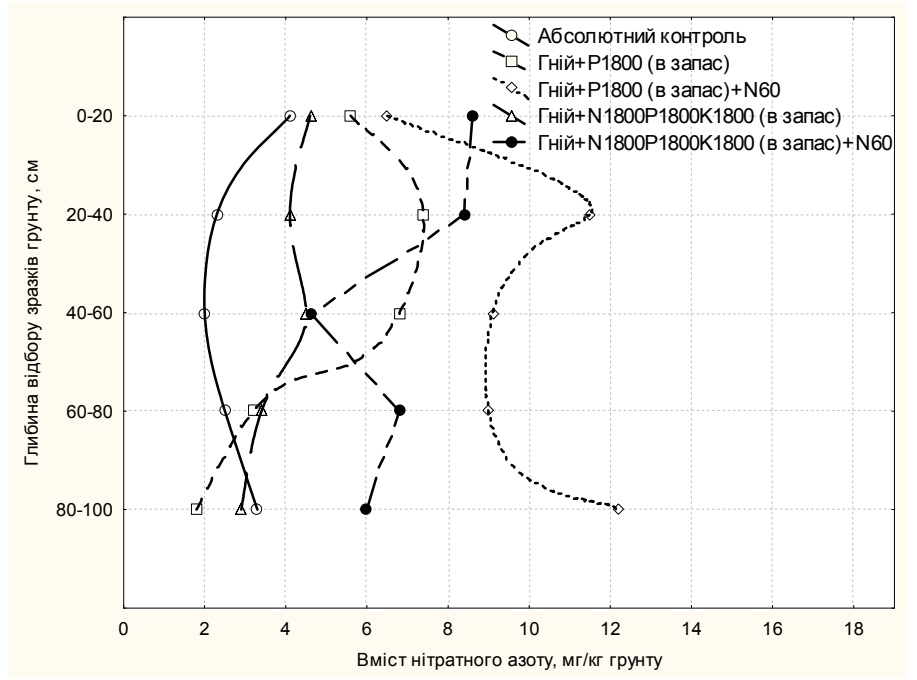

\section{The beginning of the} growing season

\section{End of the vegetation}



Fig. 3. Dynamics of nitrate nitrogen during the growing season in 2016 and change in its content by profile of typical chernozem

In the variant with the reserve application of phosphorus fertilizers (manure $+P_{1800}$ ) compared with the control variant in both years of research was defined the increase in the content of nitrate nitrogen by the profile of the soil (in 2016 in 1,3-1,4 times and in 2017 in 1,1-2.2 times). These results confirm the synergistic effect of nitrogen and phosphorus ions, even with the phosphorus application into the reserve. However, under adverse environmental conditions in 2017, significantly lower concentrations of nitrate nitrogen in the soil were recorded compared to the optimal wetting of 2016 at the beginning of the vegetation (1.2-2.9 times) and at the end of the growing season ( in 2,6-3,5 times). 


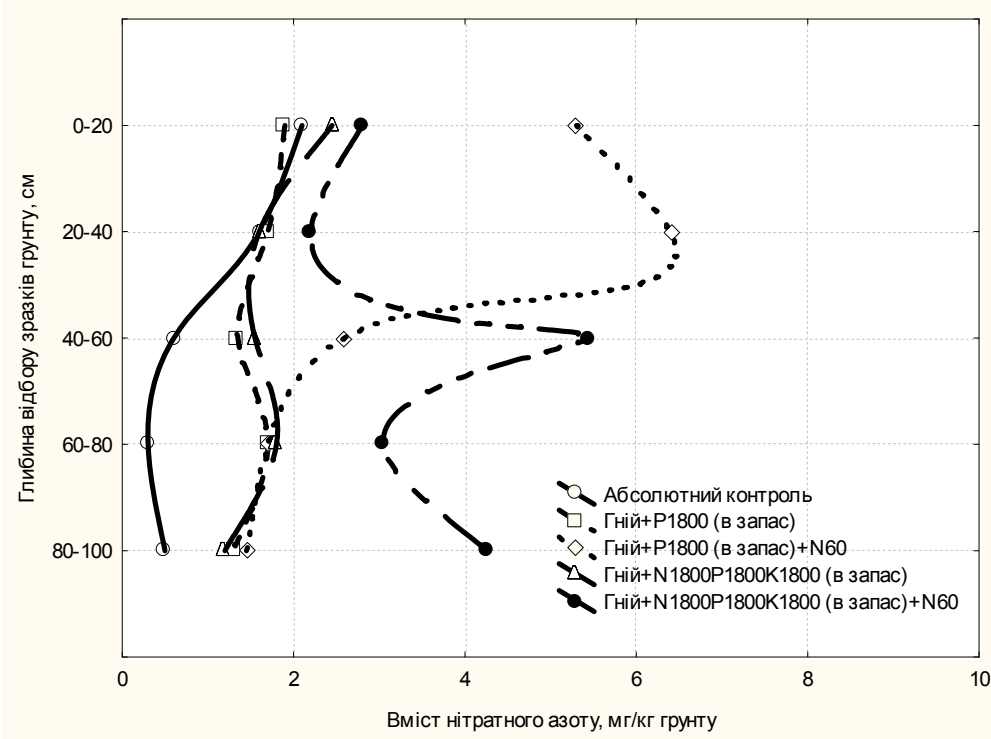

The beginning of the growing season

\section{End of the vegetation}

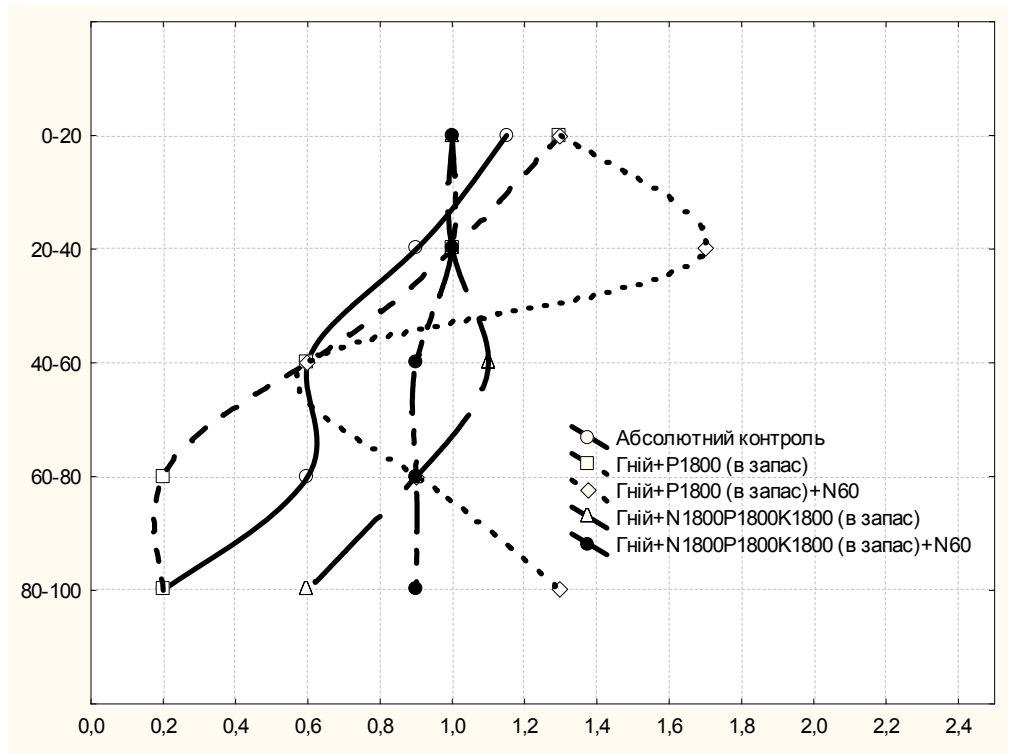

Fig. 4. Dynamics of nitrate nitrogen during the growing season in 2017 and change in its content by profile of typical chernozem

It should be noted that the end of the growing season in 2017 was characterized by a more significant difference in the content of nitrate nitrogen, especially in the upper layers of soil (fig. 3,4 ), which is again due to the predominance in the structure of mineral nitrogen of its ammonium forms, which practically have not been transformed into nitrates due to the lower activity of microbiological processes in the redissolved upper layer of chernozem typical.

The research established a close relationship between the content of nitrate nitrogen in the profile of chernozem typical and soil moisture, the correlation coefficient between these indicators was 0.53 (fig. 5). At the same time, the maximum moisture content in the $0-100 \mathrm{~cm}$ layer of chernozem typical was observed, as well as mineral nitrogen reserves, on the agrochemical background with the application of phosphate fertilizers into the reserve. Such data indicates the interdependence of these two indicators the efficiency of the use of nutrients, primarily nitrogen, depends on the available moisture of the soil, in turn, the effectiveness of the use of moisture depends on the availability of the necessary nutrients for the formation of the crop. In addition, studies have found that the preservation of moisture reserves and, consequently, its more efficient using by plants in arid 2017 year was higher in the background of the application of phosphate fertilizers in reserve compared with control option as well as at the beginning of 
the vegetation and in the end (by $5.4 \%$ and $2,1 \%$, respectively), and with nitrogen top-dressing in this background, moisture reserves were even higher by $11,6 \%$ and $8,4 \%$ compared with the control variant.

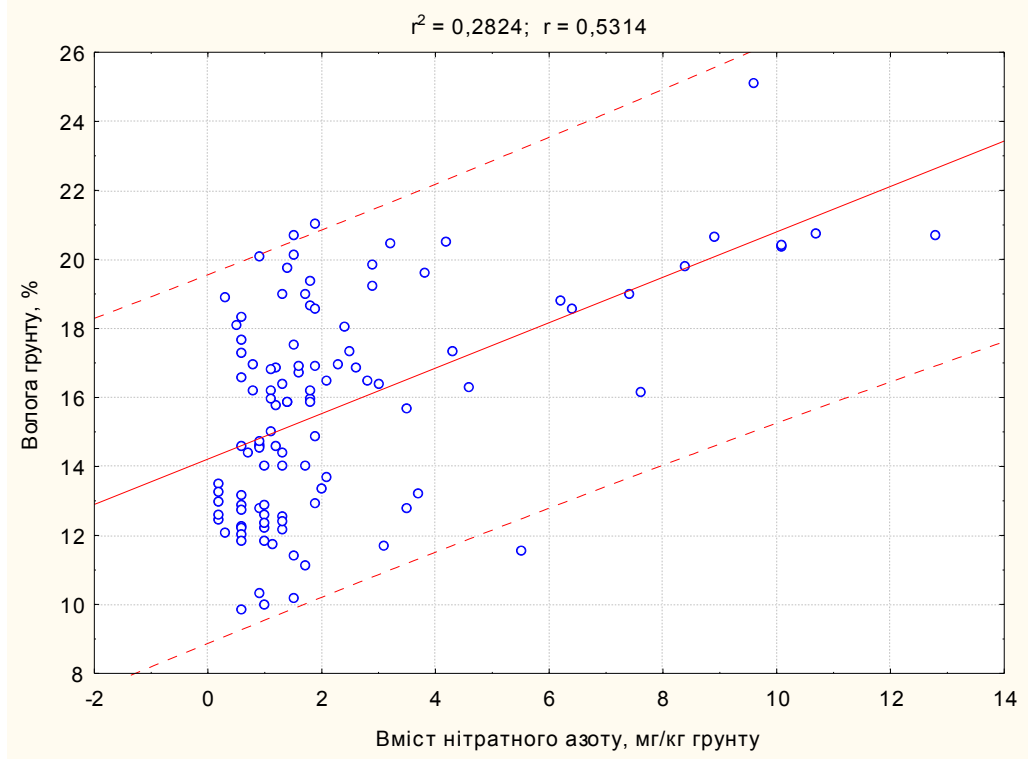

Fig. 7. Correlation dependence of the content of nitrate nitrogen and moisture in $0-100 \mathrm{~cm}$ layer of chernozem typical

The obtained regularities of the dynamics of mineral forms of nitrogen and moisture of soil on agrochemical backgrounds, which were investigated in different weather conditions, affected the yields of agricultural crops (maize for silage and spring barley). Under conditions of insufficient humidification, the efficiency of nutrient uptake by nitrogen largely depended on the provision of soil with phosphorus, the same regularity is observed for sufficient moisture, but the efficiency of nutrition is significantly reduced (table 1).

1. Efficiency of nitrogen top-dressing depending on the maintenance of macro elements under different humidity conditions

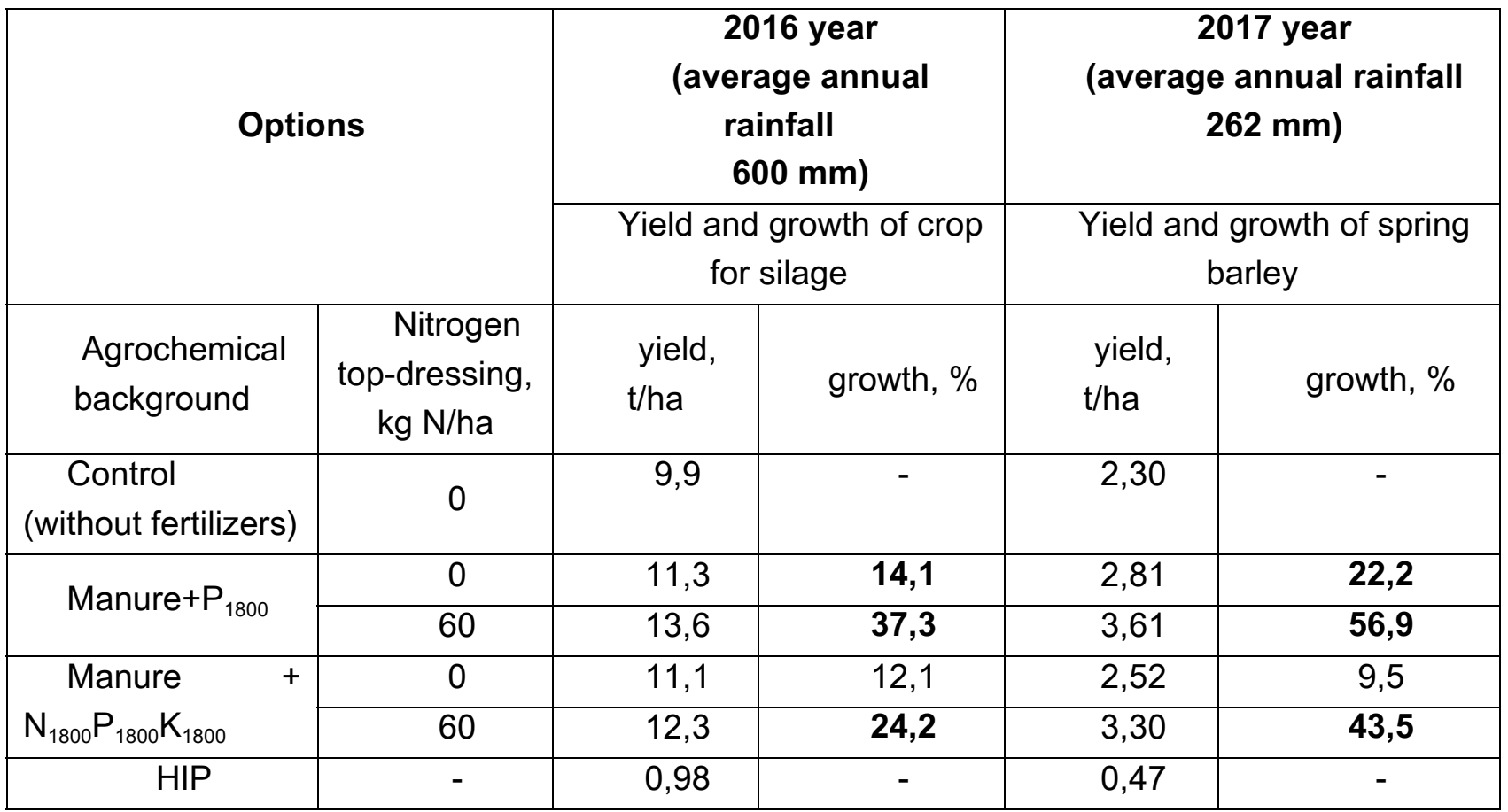

In extreme weather conditions of 2017 year, when in the beginning of the vegetation, $0-100 \mathrm{~cm}$ of productive moisture in the soil layer was evaluated as insufficient, at the end of the vegetation, as very 
low, on high agrochemical backgrounds, the nitrogen fertilization efficiency was higher compared to the optimum wetting of 2016 year, which was reflected in an increase in the growth of spring barley crops in 1.5-1.8 times compared with the growth of crop for silage.

\section{Conclusions}

Investigations of the regularities of seasonal dynamics of macroelements and the peculiarities of their redistribution in the soil during the vegetation period of the years differing in water availability are established: 1) a significant decrease in the activity of mineral nitrogen using by plants under stress conditions and the predominance in the structure of mineral nitrogen of its ammonium forms, especially at the end of the vegetation, which is probably due to the inhibition of the transformation of ammonium nitrogen forms in nitrates because the inhibition of microbiological processes in arid years; 2) a significant increase in the efficiency of both nitrogen and soil moisture utilization by plants in the dry year was determined by the application of phosphate fertilizers into the reserve as well as at the beginning of the vegetation and at the end.

Consequently, the optimization of plant root nutrition due to the introduction of mineral fertilizers, in particular phosphorous, allows to substantially expand the range of soil moisture.

\section{Bibliography}

1. Kadichegova A.N., Chuprova V.V., Kadichegov V.A. (2009). Dynamics of mobile nitrogen compounds in agro-chernozem with texture-carbonate under bean cultures. Vestnik KrasGaU: Soil Science. No. 8. P. 519-526.

2. Amtmann A., Blatt M.R. (2009). Regulation of macronutrient transport. New Phytol. V. 181(1). Pp. 35-52. doi: 10.1111/j.1469-8137.2008.02666.x.

3. Sardans J., Peñuelas J. (2007). Drought changes the dynamics of trace element accumulation in a Mediterranean Quercus ilex forest. Environ Pollut. V. 147(3). P. 567-83.

4. Sardans J., Peñuelas J., Estiarte M. (2008). Warming and drought change trace element bioaccumulation patterns in a Mediterranean shrubland. Chemosphere. 2008. V. 70 (5). P. 874-885.

5. Marschner $\mathrm{H}$. Effect of mineral nutritional status on shoot-root partitioning of photo assimilates and cycling of mineral nutrients / H. Marschner, E.A. Kirkby, I. Cakmak // J Exp Bot. - 1996. - V. 47. Pp.1255-1263.

6. Nosko B.S. (1981). Using the method of background simulation in the study of agrochemical properties of soils. Agrochemicals J. No. 1. P. $122-127$.

7. Marschner H. (1995). Mineral Nutrition of Higher Plants. Academic Press, London, U.K. - P. 889.

8. Hassan M.J., Wang F., Ali S., Zhang G. (2005). Toxic effects of cadmium on rice as affected by nitrogen fertilizer form. Plant Soil. V. 277. P. 359-365.

9. Tisdale S.L., Nelson W.L. (1975). Elements required in plant nutrition, in Soil fertility and fertilizers. Macmillan Publishing Co., Inc., New York, NY, U.S.A. P. 66-104.

10. Waraich E.A., Amad R., Ashraf M.Y. (2011). Ahmad M.Improving agricultural water use efficiency by nutrient management. Acta Agri Scandi - Soil \& Plant Sci. V. 61(4). P. 291-304.

11. Miroshnychenko N.N. Revtie-Uvarova A.V., Hladkikh Ye.Yu. (2017). Convergence of methods for determining the trophic state of soils. Materials of the international scientific conference devoted to the 120th anniversary of the birth of Academician Ion Dikusar, September 6-7, Chisinau (Republic of Moldova). P. 343-350. 